\title{
Ovarian cancer subtypes and survival in relation to three comprehensive imaging parameters
}

\author{
Hanna Sartor ${ }^{1 *}$ (D) Maria Bjurberg ${ }^{2}$, Mihaela Asp ${ }^{3}$, Anna Kahn', Jenny Brändstedt ${ }^{2}$, Päivi Kannisto ${ }^{3}$ and Karin Jirström²
}

\begin{abstract}
Background: Ovarian cancer (OC) is usually detected in late clinical stages, and imaging at diagnosis is crucial. Peritoneal carcinomatosis (PC) and cardio phrenic lymph nodes (CPLN) are pathological findings of computed tomography (CT) and are relevant for surgical planning. Furthermore, mammographic breast density (BD) has shown an association with $\mathrm{OC}$ risk and might be prognostically relevant. However, it is not known if $P C, C P L N$, and $\mathrm{BD}$ are associated with aggressive $\mathrm{OC}$ subtypes and impaired $\mathrm{OC}$ survival. Herein, we investigated associations between three comprehensive image parameters and $\mathrm{OC}$ subtypes and survival.

Methods: The Malmö Diet and Cancer Study is a prospective study that included 17,035 women (1991-1996). Tumor information on 159 OC and information on OC specific survival (last follow-up, 2017-12-31) was registered. The CT and mammography closest to diagnosis were evaluated (Peritoneal Carcinomatosis Index PCl, CPLN, and $\mathrm{BD}$ ). Associations between $\mathrm{CT}-\mathrm{PCl}, \mathrm{CPLN}$, and BD vs. clinical stage [stage I vs. advanced stage (II-IV), histological type/grade (high grade serous and endometrioid vs. other subtypes], and OC-specific survival were analyzed by logistic and Cox regression.
\end{abstract}

Results: There was a significant association between higher CT-PCl score and advanced clinical stage (adjusted OR 1.26 (1.07-1.49)), adjusted for age at diagnosis and histological type/grade. Increasing CT-PCI was significantly associated with impaired OC specific survival (adjusted HR 1.04 (1.01-1.07)), adjusted for age at diagnosis, histological type/grade, and clinical stage. There was no significant association between $\mathrm{PCl}$ and histological type/ grade, nor between BD or CPLN vs. the studied outcomes.

Conclusions: Image PCl score was significantly associated with advanced clinical stages and impaired OC survival. An objective approach (based on imaging) to scoring peritoneal carcinomatosis in ovarian cancer could help surgeons and oncologists to optimize surgical planning, treatment, and care.

Keywords: Ovarian Cancer, Peritoneal Carcinomatosis, Lymph nodes, Breast density, Survival analyses

\section{Background}

Ovarian cancer is the seventh most common cancer and the eighth leading cause of death from cancer in women globally, and its incidence rates are highest in more

\footnotetext{
* Correspondence: hanna.sartor@med.lu.se

'Diagnostic Radiology, Department of Translational Medicine, Lund University, Skåne University Hospital, Lund, Sweden

Full list of author information is available at the end of the article
}

developed regions [1]. Also, women are often diagnosed at a late stage of the disease since ovarian cancer presents late and with diffuse clinical symptoms, such as vague abdominal pain or malaise [2]. Due to the late diagnosis, it is crucial to optimize imaging and treatment at time of diagnosis.

Computed tomography (CT) is often the first test with which ovarian cancer is detected [3]. One of the most

C C The Author(s). 2020 Open Access This article is licensed under a Creative Commons Attribution 4.0 International License, which permits use, sharing, adaptation, distribution and reproduction in any medium or format, as long as you give appropriate credit to the original author(s) and the source, provide a link to the Creative Commons licence, and indicate if changes were made. The images or other third party material in this article are included in the article's Creative Commons licence, unless indicated otherwise in a credit line to the material. If material is not included in the article's Creative Commons licence and your intended use is not permitted by statutory regulation or exceeds the permitted use, you will need to obtain permission directly from the copyright holder. To view a copy of this licence, visit http://creativecommons.org/licenses/by/4.0/ The Creative Commons Public Domain Dedication waiver (http://creativecommons.org/publicdomain/zero/1.0/) applies to the data made available in this article, unless otherwise stated in a credit line to the data. 
common findings is peritoneal metastases that can be evaluated with CT with an overall sensitivity of more than $90 \%$ (depending on anatomical site, lesion size, and radiologist experience) and with high specificity (around $80 \%)$ as compared to findings at surgery $[4,5]$. The Sugarbaker peritoneal carcinomatosis index (PCI) [6] allows a quantification of peritoneal metastases both surgically [7] and with imaging [5], and previous studies have reported that CT-PCI has the potential to help evaluate surgical outcome [8] and the 5-year survival probability in women with advanced ovarian cancer [9].

Furthermore, cardio phrenic lymph nodes (CPLN) are located above the abdominal cavity and diaphragm and are, by convention, considered radiologically positive if the short axis in the transaxial plane is $\geq 5 \mathrm{~mm}$. However, how they should be handled in surgical care and their role in ovarian cancer prognosis have been debated [10, 11]. Interestingly, a recent paper (predominantly high grade serous $\mathrm{OC}$ ) [10] indicated that there was a stronger correlation between CPLN positivity and peritoneal carcinomatosis of the upper abdomen (especially of the diaphragm) than between CPLN positivity and abdominal lymph node status, which makes the two parameters (CT-PCI and CPLN) particularly interesting to study together.

Women in developed countries are frequently subject to imaging as part of breast cancer-screening programs that include mammography. Mammographic breast density (BD) is an image parameter that reflects the composition of the breast tissue, and women with dense breasts have a higher incidence of breast cancer than do women with non-dense breasts and possibly also a worse prognosis [12, 13]. Also, increased BD has also been shown to be associated with a modestly increased risk of ovarian cancer [14]. However, it is not known if BD is linked to more aggressive types of ovarian cancer in terms of stage, histological grade, and survival, and this has not been previously studied.

Imaging is an underused biomarker since it has the potential to aid in the prediction of clinical decision making and prognosis. However, currently, in clinical routines addressing ovarian cancer, imagining is not used in a structured manner. However, it is a challenge to select relevant imaging parameters, which must be both readily available and pragmatic to analyze for the radiologist. The joint initiative on several imaging parameters in relation to long term follow up in ovarian cancer has the possibility to represent such relevant imaging parameters and has, to the best of our knowledge, not previously been investigated.

The goal of this study was to analyze three comprehensive imaging parameters available for most women with ovarian cancer, with the hypothesis that these might add information on ovarian cancer subtypes and survival at an early diagnostic stage.

\section{Methods}

The Malmö diet and Cancer study (MDCS)

The MDCS (LU 51-90) and the present study (Dnr 530/ 2008) were approved by the regional ethics committee in Lund, Sweden. All women gave written informed consent.

The MDCS [15-17] was a population-based, prospective cohort study, which included 17,035 women during 1991-1996. Various baseline data were registered (e.g., parity, oral contraceptives), and ovarian cancer cases were identified prospectively from the MDCS cohort. The associated pathological (histological subtype and grade, clinical stage) and radiological variables at ovarian cancer diagnosis (mammographic density, CT-PCI, CPLN) were collected and added to the database retrospectively for research purposes. Cause of death (ovarian cancer as an underlying or subordinate cause of death) and vital status (alive or dead from another cause was classified as alive) was registered with the last follow-up on 31 December 2017 (mean follow up time, 16.7 years).

\section{CT-PCl and CPLN}

Patients with digital CT images were eligible for image analyses. Hence, patients with analogue CT images are classified as "missing CT" (Table 1). All patients underwent $\mathrm{CT}$ in the supine position and the majority with intravenous and oral contrast. Images were reformatted in the coronal and sagittal planes. The images were gathered over a long period of time. Hence, there is a variety of radiology systems; this has, however, been shown not to affect peritoneal carcinomatosis detection [4]. The median time between CT closest to diagnosis and registered OC diagnosis was 6 days (range 152 days). CT-PCI was retrospectively scored using the Sugarbaker classification $[5,6]$ by one specialist in radiology with subspeciality training in gastroradiology (CB). The PCI is calculated as the sum of numerical lesion scores assigned to 13 abdominopelvic regions. The lesion score relates to the largest visible implant. CPLN was defined as pathologically enlarged if measuring $\geq 5 \mathrm{~mm}$ in the short axis in the axial plane [10] and was defined as negative or positive (i.e., enlarged). The evaluation of CPLN was made on the same CT as for CT-PCI and was retrospectively analyzed by one radiologist with subspecialty training in gastroradiology (AK).

\section{Breast density}

BD was retrospectively graded in one of four categories (a-d) according to Breast Imaging Reporting and Data System 5th Ed (BI-RADS) [18] using the screening mammography (analogue (before year 2004) or digital) closest before ovarian cancer diagnosis (median, 1.2 years). The BD was estimated using both breasts and all views. All mammograms were assessed by one specialist in radiology with special training in $\mathrm{BD}(\mathrm{HS})$. 
Table 1 Imaging parameters and patient and tumor characteristics in relation to ovarian cancer-specific survival

\begin{tabular}{|c|c|c|}
\hline & Alive & Dead \\
\hline \multicolumn{3}{|l|}{ Age at diagnosis } \\
\hline$n$ & 58 & 101 \\
\hline median (range) & $68(37)$ & $68(40)$ \\
\hline Missing & 0 & 0 \\
\hline \multicolumn{3}{|l|}{ Parity } \\
\hline Nullipara & $8(14.0)$ & $23(23.2)$ \\
\hline Yes & $49(86.0)$ & $76(76.8)$ \\
\hline Missing & 1 & 2 \\
\hline \multicolumn{3}{|l|}{ Oral contraceptives } \\
\hline No & $31(53.5)$ & $54(53.5)$ \\
\hline Yes & $27(46.5)$ & $47(46.5)$ \\
\hline Missing & 0 & 0 \\
\hline \multicolumn{3}{|l|}{ Density } \\
\hline Low & $22(50)$ & $29(46.8)$ \\
\hline High & $22(50)$ & $33(53.2)$ \\
\hline Missing & 14 & 39 \\
\hline \multicolumn{3}{|l|}{ Stage } \\
\hline Stage I & $19(32.8)$ & $7(7.2)$ \\
\hline Advanced Stage & $39(67.2)$ & $90(92.8)$ \\
\hline Missing & 0 & 4 \\
\hline \multicolumn{3}{|l|}{ Histological type/grade } \\
\hline Low grade serous/other & $22(38.6)$ & $24(24.7)$ \\
\hline $\begin{array}{l}\text { High grade serous and all } \\
\text { endometroid }\end{array}$ & $35(61.4)$ & $73(75.3)$ \\
\hline Missing & 1 & 4 \\
\hline \multicolumn{3}{|l|}{$\mathrm{PCl}$} \\
\hline median (range) & $2.5(39)$ & $17.5(39)$ \\
\hline Missing $C T$ & 16 & 49 \\
\hline \multicolumn{3}{|l|}{ CPLN } \\
\hline$<5 \mathrm{~mm}$ & $24(57.1)$ & $22(42.3)$ \\
\hline$\geq 5 \mathrm{~mm}$ & $18(42.9)$ & $30(57.7)$ \\
\hline Missing CT & 16 & 49 \\
\hline
\end{tabular}

Categorical variables are presented as count (percent) and continuous variables are presented as median (range)

\section{Tumor characteristics and clinical stage}

All tumors between 1991 and 2007 were reevaluated by a senior pathologist $(\mathrm{KJ})$ regarding histological subtype and histological grade [19]. Information on tumors from 2008 and onward were extracted from the original pathology reports, with the reports being more structured from these time points and onwards. Of the 166 OC cases (100\%), 7 (4\%) cases were defined as non-epithelial and excluded. Of the 159 OC cases eligible for analysis, the distribution was as follows: 99 (60\%) were classified as serous, 27 (16\%) endometrioid, ten (6\%) mucinous, seven (4\%) clear-cell, and 12 (7\%) undifferentiated/ adenocarcinoma NOS, and four cases (2\%) had missing information on histologic subtype in medical charts or pathology reports. No borderline tumors were included in the study, as none had been registered. Tumor grade was divided into low or high, with the previous intermediate grade classified as high grade in this present study. Because of the small number of cases and for purposes of clinical relevance, histological subtype and grade were combined into one variable with the following classification: high-grade serous tumors and endometroid tumors (all grades) were grouped, and all other histological types combined in one group (including serous type with low or unknown grade). Information regarding the clinical stage was obtained retrospectively from the medical charts, following the standardized WHO classification of tumor staging and classified as stage I or advanced stage (II-IV).

\section{Statistics}

Logistic regression was used to analyze CT-PCI (continuous), dichotomized BD [fatty $(a+b)$ vs. dense $(c+d)]$, and CPLN (binary) in relation to histologic type/grade (binary) and clinical stage (binary), which yielded odds ratios (OR) and $95 \%$ confidence intervals (CI). Adjustments were made for age at diagnosis (continuous), oral contraceptive use at baseline (binary), and parity (binary) in density analyses. Adjustments (CT-PCI and CPLN) were made for age at diagnosis (continuous) and histologic subtype/grade or clinical stage (when the variable was not an endpoint). KaplanMeier estimates were used to present survival probabilities for breast density and CPLN, respectively. Associations between selected imaging parameters and ovarian cancer survival were analyzed using Cox's proportional hazards analysis, yielding an $\mathrm{HR}$ with a $95 \% \mathrm{CI}$; adjustments were made for age at diagnosis, histologic subtype/grade, and clinical stage with the addition of oral contraceptives and parity in density analyses. The proportional hazards assumption was confirmed using a log-minus-log plot. A $p$ value $<0.05$ was considered statistically significant. Stata SEwas used for the statistical analyses (version 16.0. College Station, Texas: StataCorp.).

\section{Results}

The imaging parameters and patient and tumor characteristics relating to ovarian cancer-specific survival are shown in Table 1. The mean difference between age at baseline and age at diagnosis was 11.3 years (range, $0.3-$ 0.24). The distribution of PCI scores over ovarian cancer-specific survival is shown in Fig. 1. Radiological images illustrating peritoneal carcinomatosis, enlarged CPLN, and breast density is shown in Figs. 2 and 3. 


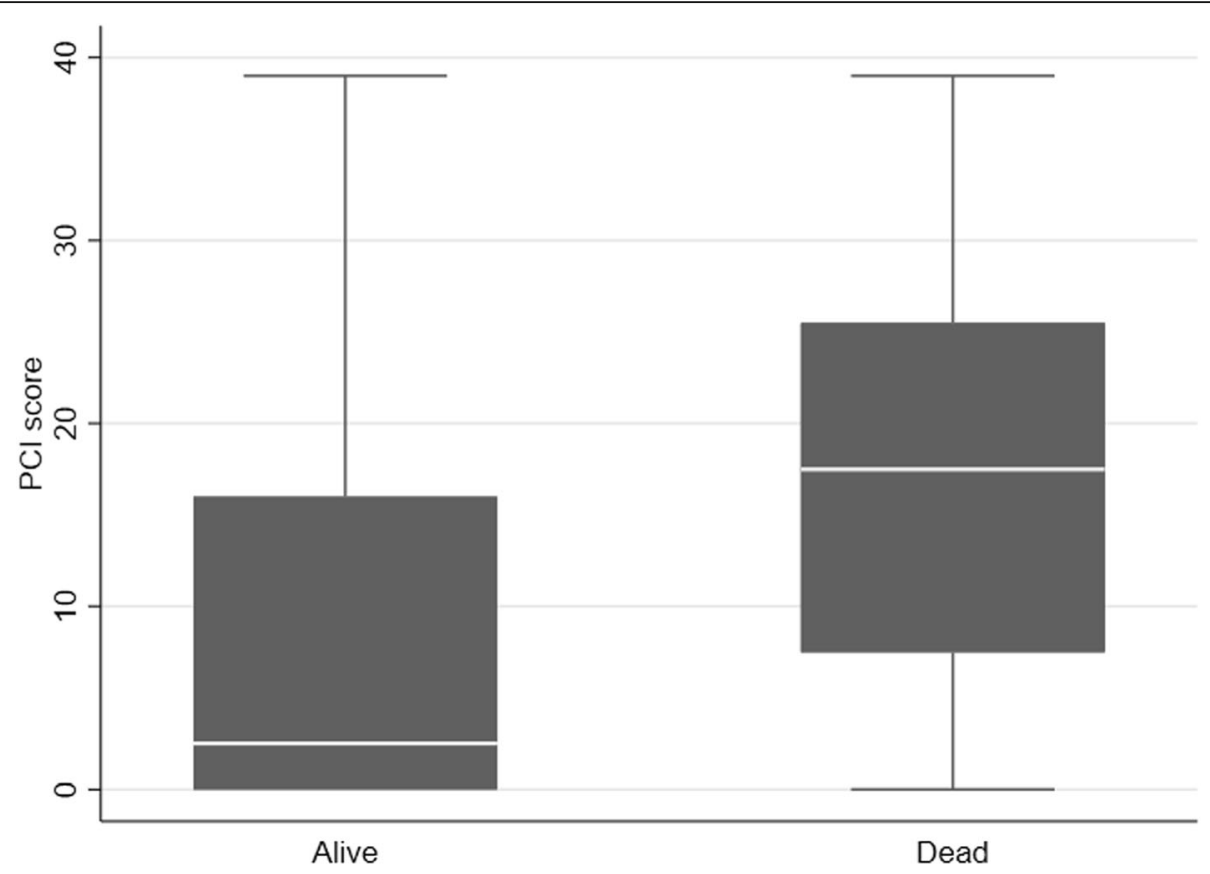

Fig. 1 Distribution of $\mathrm{PCl}$ scores over ovarian cancer-specific survival

\section{CT-peritoneal Carcinomatosis index}

There was a statistically significant association between increasing CT-PCI and advanced clinical stage ( $\mathrm{OR}_{\text {adj }} 1.26$ (1.07-1.49), $p=0.007)$, adjusted for age at diagnosis and histologic type/grade (Table 2). There was no association between CT-PCI and histologic type/grade $\left(\mathrm{OR}_{\mathrm{adj}} 1.02\right.$ (0.98-1.06), $p=0.434)$. Furthermore, higher CT-PCI was significantly associated with impaired OC specific survival
$\left(\mathrm{HR}_{\mathrm{adj}}\right.$ 1.04 (1.01-1.07), $\left.p=0.003\right)$, adjusted for age at diagnosis, histologic type/grade, and clinical stage.

\section{Cardiophrenic lymph nodes}

In crude analyses, there was a statistically significant association between enlarged CPLN and advanced clinical stage (OR 3.14 (1.10-10.57), $p=0.033$ ) (Table 3). After adjustments, the association was in the same direction

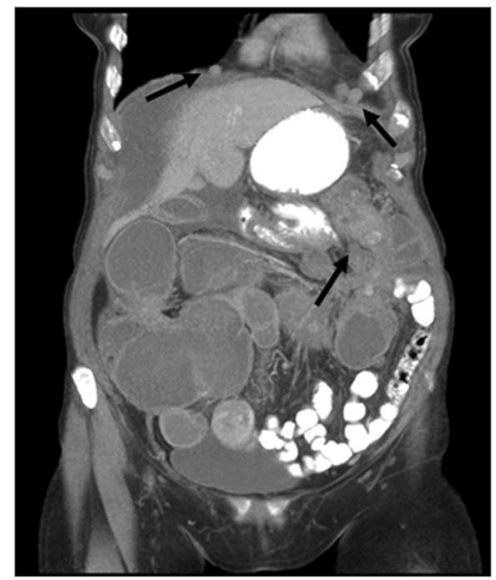

a

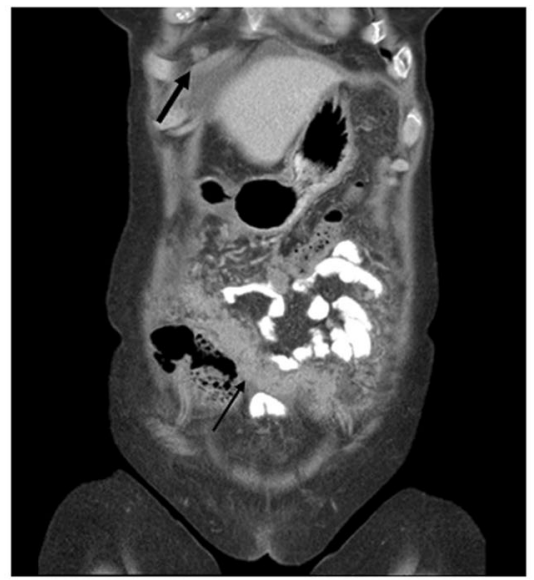

b

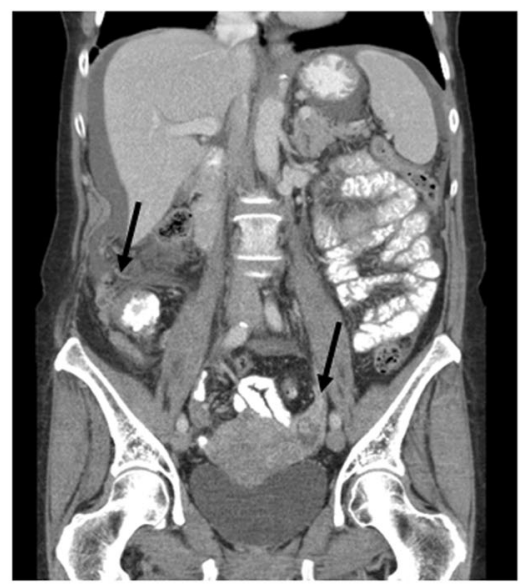

C

Fig. 2 Peritoneal carcinomatosis and CPLN in women with ovarian cancer. a CT-image (coronary projection) showing bilateral enlarged CPLN and peritoneal carcinomatosis primarily affecting left side intestines, causing obstruction. b CT-image (coronary projection) showing ventral carcinomatosis, i.e. omental cake and enlarged CPLN. c CT-image (coronary projection, same examination as b) showing a left sided ovarian mass and diffusely spread carcinomatosis primarily affecting right sided colon 


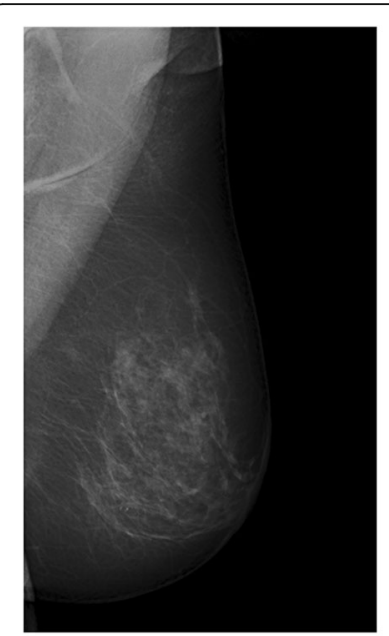

a

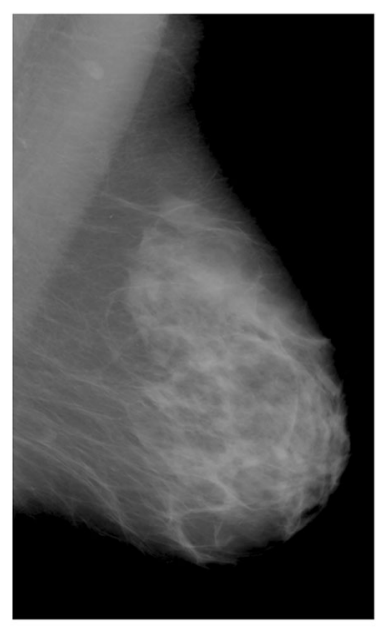

b
Fig. 3 Breast density in women with ovarian cancer. a Mammography showing a fat involuted breast. b Mammography showing a dense breast

although not significant (OR adj 2.13 (0.69-7.66), $p=$ $0.173)$. There were no statistically significant associations between enlarged CPLN and histologic type/grade or OC specific survival. However, for both analyses enlarged CPLNs were more frequent with high grade tumors as compared to low grade tumors $(57.1 \%$ vs. $41.7 \%)$ and more frequent with OC deaths vs. alive cases $(57.7 \%$ vs. 42.9\%). The non-significant difference in survival between the two groups of CPLN is further illustrated in Fig. 4.

\section{Breast density}

There were no significant associations between high BD and clinical stage $\left(\mathrm{OR}_{\mathrm{adj}} 1.65(0.57-4.78), p=0.361\right)$ or histologic type/grade $\left(\mathrm{OR}_{\mathrm{adj}} 1.13(0.46-2.79), p=0.787\right)$, adjusted for age at diagnosis, parity, and oral contraceptives. Also, high $\mathrm{BD}$ showed no relation to $\mathrm{OC}$ specific survival $\left(\mathrm{OR}_{\mathrm{adj}} 0.90(0.52-1.56), p=0.708\right)$, adjusted for age at diagnosis, histological type/grade, clinical stage, parity, and oral contraceptives. The relation between the two groups of density and survival is further illustrated in Fig. 5. All analyses with adjustments are shown in Table 4.

\section{Discussion}

In this study, we have identified significant relationships between CT-PCI, advanced clinical stage, and longtime follow-up ovarian cancer-specific survival. CPLN and mammographic density did not show a relationship with ovarian cancer subtypes or survival. From an imaging point of view, this demonstrates how structured reporting of peritoneal carcinomatosis can aid in clinical care.

Many factors affect the sensitivity of CT for detecting peritoneal carcinomatosis, such as lesion size, ascites, and technical parameters. However, CT is still considered the imaging method of choice for detecting ovarian tumors and peritoneal implants [20]. According to a previous meta-analysis on malignancies with peritoneal metastasis (of which $46 \%$ had a gynecological origin), CT is reported to underestimate carcinomatosis by $12-33 \%$ [21], but there was still a moderate to high agreement between CT-PCI scores and surgical-PCI scores (kappa = 0.49 to 0.96 ) [21]. Furthermore, we believe that patient outcome is particularly interesting to highlight and is likely more relevant than surgical findings as a standard of reference for imaging studies. Interestingly, CT-PCI can be used to preoperatively estimate the surgical challenges and postoperative complications in women with OC [8]. Also, Diaz et al. have shown that peritoneal disease quantified by CT-PCI in advanced-stage ovarian cancer patients correlated with presurgical CA-125 levels and 5-year survival [9]. This is in line with our results, showing increasing CT-PCI to be significantly related to impaired OC-survival, even after adjustment for histological subtype and clinical stage. Previous studies $[8,9]$ have addressed stage III and IV OC. However, we believe that it is important to include all OC stages since,

Table 2 Peritoneal Carcinomatosis Index (PCl) in relation to ovarian cancer subtypes/survival

\begin{tabular}{|c|c|c|c|c|c|c|}
\hline & \multicolumn{6}{|c|}{ Median (range) } \\
\hline & Stage I & Advanced Stage & OR $(95 \% \mathrm{Cl})$ & $p$-val & $\mathrm{OR}_{\text {Adj }}{ }^{\mathrm{a}}(95 \% \mathrm{Cl})$ & $\overline{p \text {-val }}$ \\
\hline $\mathrm{PCl}$ & $0(8)$ & $17(39)$ & $1.29(1.10-1.53)$ & 0.002 & $1.26(1.07-1.49)$ & 0.007 \\
\hline \multirow[t]{2}{*}{ Observations } & & & 92 & & 90 & \\
\hline & Low grade & High grade & OR $(95 \% \mathrm{Cl})$ & $p$-val & $\mathrm{OR}_{\mathrm{Adj}}^{\mathrm{b}}(95 \% \mathrm{Cl})$ & $p$-val \\
\hline $\mathrm{PCl}$ & $2.5(39)$ & $14(39)$ & $1.02(0.99-1.06)$ & 0.170 & $1.02(0.98-1.06)$ & 0.434 \\
\hline \multirow[t]{2}{*}{ Observations } & & & 92 & & 90 & \\
\hline & Alive & Dead & $\mathrm{HR}(95 \% \mathrm{Cl})$ & $p$-val & $\mathrm{HR}_{\text {Adj }}{ }^{\mathrm{C}}(95 \% \mathrm{Cl})$ & $p$-val \\
\hline $\mathrm{PCl}$ & $2.5(39)$ & $17.5(39)$ & $1.05(1.02-1.07)$ & $<0.001$ & $1.04(1.01-1.07)$ & 0.003 \\
\hline Observations & & & 94 & & 90 & \\
\hline
\end{tabular}

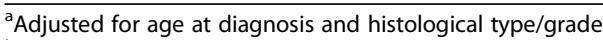

${ }^{\mathrm{b}}$ Adjusted for age at diagnosis and stage

${ }^{\mathrm{c}}$ Adjusted for age at diagnosis and stage and histological type/grade 
Table 3 Cardiophrenic lymph nodes (CPLN) in relation to ovarian cancer subtypes/survival

\begin{tabular}{|c|c|c|c|c|c|c|}
\hline & n (\%) & & & & & \\
\hline & Stage I & Advanced Stage & OR (95\% Cl) & $p$-val & $\mathrm{OR}_{\text {Adj }}{ }^{\mathrm{a}}(95 \% \mathrm{Cl})$ & $p$-val \\
\hline CPLN & & & & 0.033 & & 0.173 \\
\hline$<5 \mathrm{~mm}$ & $13(72.2)$ & $32(43.2)$ & 1.0 (Ref.) & & 1.0 (Ref.) & \\
\hline$\geq 5 \mathrm{~mm}$ & $5(27.8)$ & $42(56.8)$ & $3.14(1.10-10.57)$ & & $2.13(0.69-7.66)$ & \\
\hline Observations & & & 92 & & 90 & \\
\hline & Low grade & High grade & OR (95\% Cl) & $p$-val & $\mathrm{OR}_{\mathrm{Adj}}^{\mathrm{b}}(95 \% \mathrm{Cl})$ & $p$-val \\
\hline CPLN & & & & 0.149 & & 0.181 \\
\hline$<5 \mathrm{~mm}$ & $21(58.3)$ & $24(42.9)$ & 1.0 (Ref.) & & 1.0 (Ref.) & \\
\hline$\geq 5 \mathrm{~mm}$ & $15(41.7)$ & $32(57.1)$ & $1.87(0.80-4.36)$ & & $1.86(0.75-4.62)$ & \\
\hline Observations & & & 92 & & 90 & \\
\hline & Alive & Dead & HR (95\% Cl) & $p$-val & $\operatorname{HR}_{\text {Adj }^{c}}(95 \% \mathrm{Cl})$ & $p$-val \\
\hline CPLN & & & & 0.110 & & 0.275 \\
\hline$<5 \mathrm{~mm}$ & $24(57.1)$ & $22(42.3)$ & 1.0 (Ref.) & & 1.0 (Ref.) & \\
\hline$\geq 5 \mathrm{~mm}$ & $18(42.9)$ & $30(57.7)$ & $1.57(0.90-2.73)$ & & $1.40(0.77-2.54)$ & \\
\hline Observations & & & 94 & & 90 & \\
\hline
\end{tabular}

${ }^{a}$ Adjusted for age at diagnosis and histological type/grade

${ }^{\mathrm{b}}$ Adjusted for age at diagnosis and stage

${ }^{\mathrm{c}}$ Adjusted for age at diagnosis and stage and histological type/grade

in daily clinical practice, at the time of imaging, the clinical stage is unknown. Therefore, including all stages more adequately reflects the true clinical scenario. It would have been interesting to subdivide the CT-PCI to further investigate if certain strategic abdominal areas were over- or under-represented. However, this was not possible due to the small sample size.
We could not establish an association between CT$\mathrm{PCI}$ and histological subtypes, which is in line with the findings of a previous study (although comparing serous and non-serous tumors) [9]. However, there was a significant relationship between increasing CT-PCI and advanced stage, which, to the best of our knowledge has not been previously studied and is coherent with our

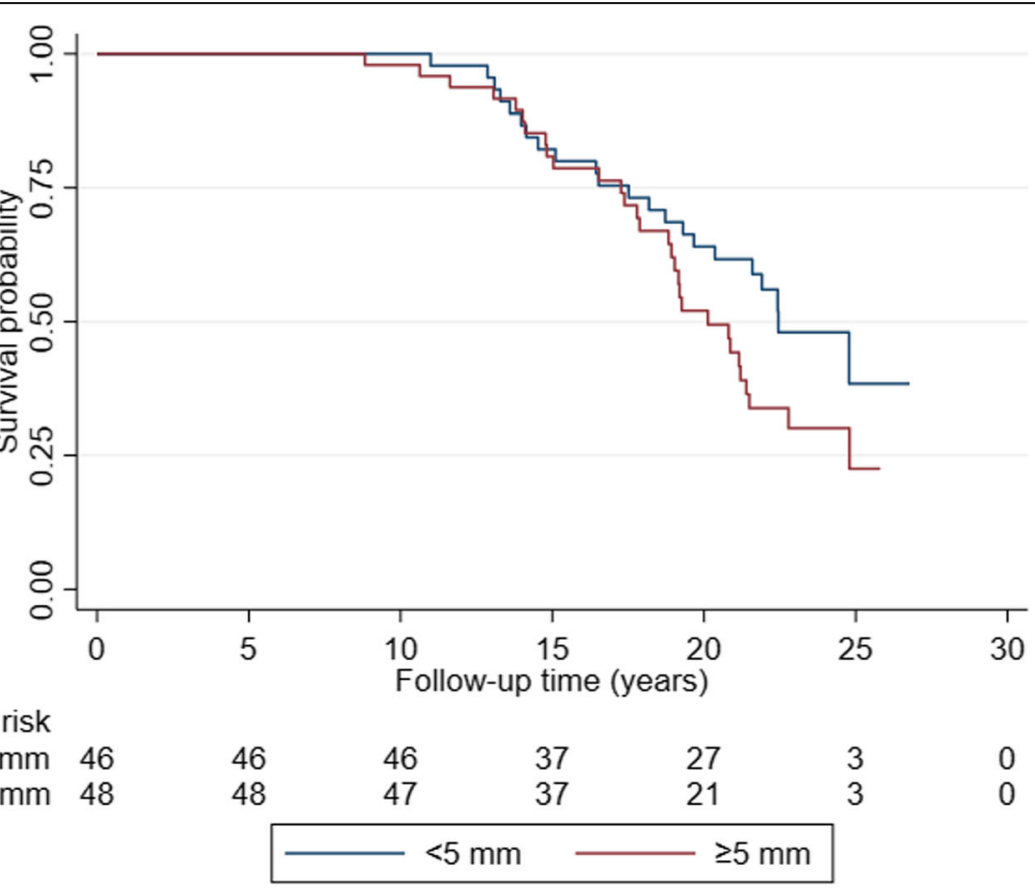

Fig. 4 CPLN in relation to ovarian cancer specific survival 


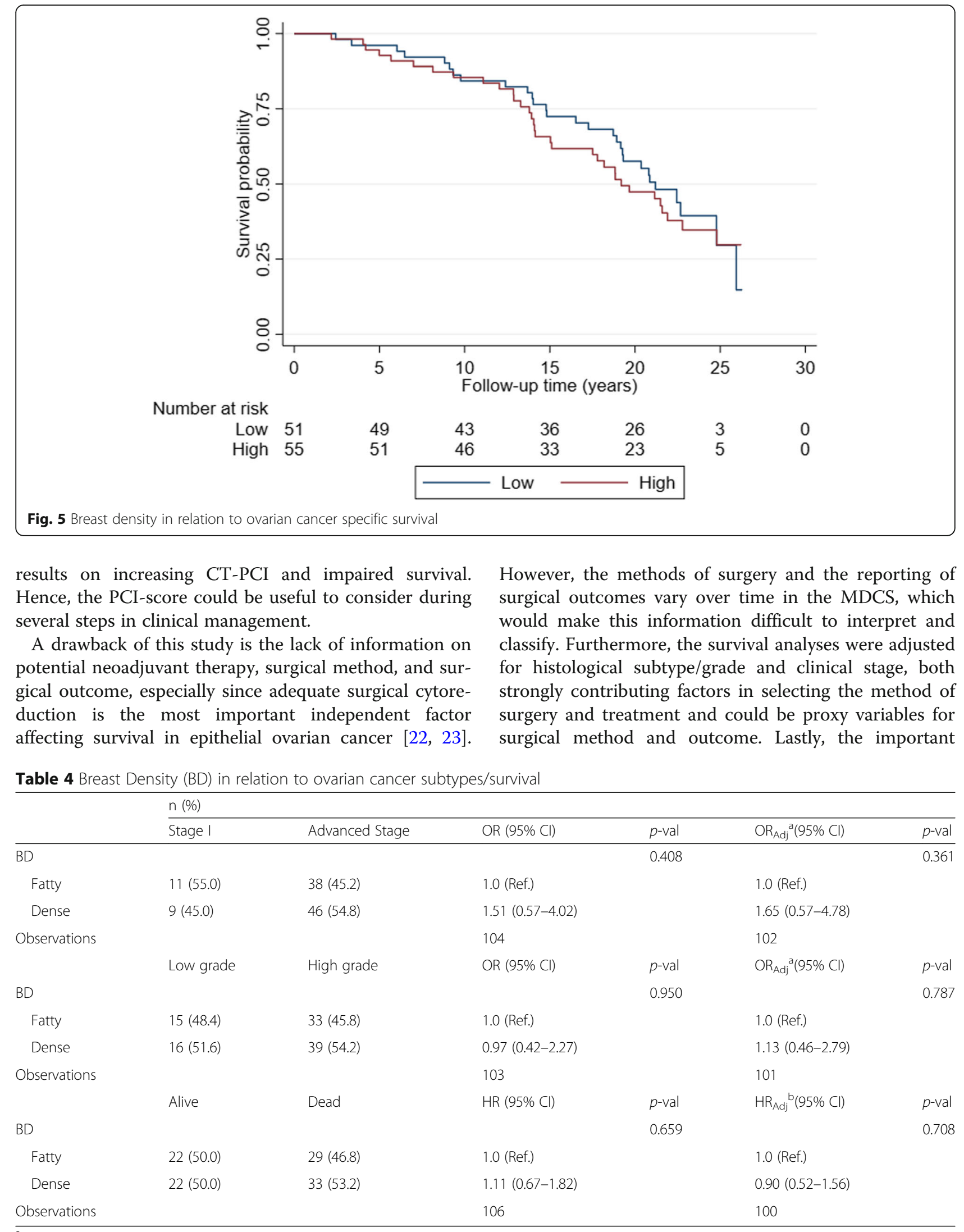

${ }^{a}$ Adjusted for age at diagnosis, parity and use of oral contraceptives

${ }^{\mathrm{b}}$ Adjusted for age at diagnosis, parity and use of oral contraceptives, stage and histological type/grade 
aspect here is not the well-known fact that increased carcinomatosis is linked to surgical difficulties and more severe stages and outcome, but rather the important fact that an image score has the potential to reliably quantify carcinomatosis with a clear link to outcome, independent of time period.

At our institution, a prospective trial on women with ovarian cancer is planned, including scoring of CT-PCI, CPLN (by at least two radiologists) and surgical-PCI, registration of patient and pathology factors at the time of diagnosis, medical and surgical treatment, and overall outcome. Taken together, evaluated and quantified CPLN and carcinomatosis through imaging can help clinicians in the surgical and prognostic dilemma early in the diagnostic procedure.

CPLN is an interesting imaging parameter since it can be retrieved from the very same CT as the PCI-score. In this study, no significant associations between CPLN size and the clinical parameters were found in the adjusted analyses. Interestingly though, for all analyses enlarged CPLN signified a more aggressive disease (advanced stage, high grade tumors, and $\mathrm{OC}$ death), which is consistent with previous knowledge [10]. Other malignancy criteria for lymph nodes (border contour and signal intensity characteristics) than the somewhat blunt size criteria have proven predictive of lymph node status in rectal cancer [24]. Additional studies with larger sample size and with additional malignancy criteria (beyond size) may be of value to further establish these associations.

Regarding BD, Wernli et al. have recently reported an association between increased BD and a moderately increased risk of ovarian cancer in women of 50-59 years of age [14]. To our knowledge, there is no previous study on $\mathrm{BD}$ and $\mathrm{OC}$ survival. Our hypothesis was that high $\mathrm{BD}$ would be associated with more aggressive OC subtypes and impaired survival; however, this could not be established. One potential reason for this is that the time between screening mammography and $\mathrm{OC}$ diagnosis varied up to 2.5 years, hence the mammographic imaging parameter and the $\mathrm{OC}$ diagnosis are not from the same time point, and the BD might have been altered during this period. Unfortunately, BRCA status was not available in the MDCS cohort, which would have been valuable considering the link to both ovarian and breast cancer [25].

This retrospective cohort study is limited by the small sample size, mostly because only digital images could be used, and results should be interpreted with caution. However, there was no large difference in the distribution of clinical stage between the group with missing data as compared to the group without missing data (regarding PCI/CPLN and density groups), hence we believe the risk of selective bias to be very low. In addition, the images were performed on different radiology systems with varying image quality due to the long-time period. On the other hand, the long observation time is also an advantage considering follow-up time for survival information. Each of the three imaging parameters (CT-PCI, mammographic density, and CPLN) was estimated by a single radiologist, which does not allow for an analysis of inter-reader variability and reproducibility. However, the purpose of this study was no to create cut-offs for survival probability, but rather to study the direction of influences of certain imaging parameters that could be of value for future study and potential implementation in structured CT reports. As highlighted by Laghi et al. [21], the CT-PCI is a challenging interpretation for radiologists since the score has some uncertainties (e.g., when it comes to abdominal area and lesion characterization), which might be difficult to score correctly. As a future prospect, it would be valuable to develop a more straightforward score, but this was beyond the scope of this study. However, given the uncertainties of the score, it is even more interesting that we were able to show a clear association with OC survival in this study.

Our results have several clinical implications. One of the very first steps, when a woman is presenting with a suspicion of ovarian cancer, is to perform a CT scan. Therefore, the structured information gathered at imaging might impact early clinical management, such as a high CT-PCI score prompting the clinical management at a specialist clinic for ovarian cancer, or to be prepared for an advanced stage disease with both surgical and prognostic challenges. Our results fit well with the structured surgical report from the European Society of Gynecological Oncology (ESGO), where surgical PCI is included in the surgical report, and as a future goal, the CT-PCI may be added to this chart.

\section{Conclusions}

We have identified significant relationships between increasing CT-PCI and important clinical parameters, such as advanced stage and impaired OC specific survival. When taken together, imaging parameters have the possibility to aid in the clinical care of women with ovarian cancer.

\footnotetext{
Abbreviations

BD: Breast density; BI-RADS: Breast imaging report and data system; $\mathrm{Cl}$ : Confidence interval; CPLN: Cardio phrenic lymph nodes; CT: Computer tomography; OC: Ovarian cancer; PC: Peritoneal carcinomatosis; $\mathrm{PCl}$ : Peritoneal carcinomatosis index

Acknowledgements

Anna Åkesson for statistical support. Carina Bursjöö for CT-PCl interpretation. Anna Hwasser for data management.

\section{Authors' contributions}

$\mathrm{HS}$ is the main contributor to study design, data collection, statistical plan, data interpretation, and manuscript draft/revision. MB participated in designing the study, data collection and interpretation, and manuscript revision. KJ participated in data collection, study design, data interpretation, and revision of the manuscript. JB participated in data collection and
} 
critically revised the manuscript. AK assisted with radiological data collection and critically revised the manuscript. PK and MA assisted with gynecological expertise in study design, data interpretation, and manuscript revision. All authors have read and approved the final manuscript.

\section{Funding}

This work was supported by Governmental Funding of Clinical Research within National Health Services. The funding resources had no role in the study design, data collection, analyses, data interpretation, writing of the manuscript, or the decision to submit the manuscript for publication. Open access funding provided by Lund University.

\section{Availability of data and materials}

The datasets used and/or analysed during the current study are available from the corresponding author on reasonable request.

\section{Ethics approval and consent to participate}

All procedures performed in studies involving human participants were in accordance with the ethical standards of the institutional and/or national research committee and with the 1964 Helsinki declaration and its later amendments or comparable ethical standards. The study was approved by the Regional Ethics Committee in Lund, Sweden (committee's reference number: LU 51-90 and 530/2008). Informed consent was obtained from individual participants included in the study.

\section{Consent for publication}

Not applicable.

\section{Competing interests}

The authors declare that they have no competing interest.

\section{Author details}

'Diagnostic Radiology, Department of Translational Medicine, Lund University, Skåne University Hospital, Lund, Sweden. ${ }^{2}$ Oncology and Pathology, Department of Clinical Sciences, Lund University, Lund, Sweden. ${ }^{3}$ Obstetrics and Gynecology, Department of Clinical Sciences, Lund University, Lund, Sweden.

Received: 16 December 2019 Accepted: 19 February 2020 Published online: 07 March 2020

\section{References}

1. Ferlay J, Soerjomataram I, Dikshit R, Eser S, Mathers C, Rebelo M, et al. Cancer incidence and mortality worldwide: sources, methods and major patterns in GLOBOCAN 2012. Int J Cancer. 2015;136(5):E359-86.

2. Doubeni CA, Doubeni AR, Myers AE. Diagnosis and Management of Ovarian Cancer. Am Fam Physician. 2016:93(11):937-44.

3. Iyer VR, Lee SI. MRI, CT, and PET/CT for ovarian Cancer detection and adnexal lesion characterization. Am J Roentgenol. 2010;194(2):311-21.

4. Chandrashekhara SH, Thulkar S, Srivastava DN, Kumar L, Hariprasad R, Kumar $\mathrm{S}$, et al. Pre-operative evaluation of peritoneal deposits using multidetector computed tomography in ovarian cancer. Br J Radiol. 2011;84(997):38-43.

5. Duhr CD, Kenn W, Kickuth R, Kerscher AG, Germer C-T, Hahn D, et al. Optimizing of preoperative computed tomography for diagnosis in patients with peritoneal carcinomatosis. World J Surg Oncol. 2011;9(1):171.

6. Jacquet $\mathrm{P}$, Sugarbaker $\mathrm{PH}$. Clinical research methodologies in diagnosis and staging of patients with peritoneal carcinomatosis. Cancer Treat Res. 1996; 82:359-74

7. Gasimli K, Braicu El, Richter R, Chekerov R, Sehouli J. Prognostic and predictive value of the peritoneal Cancer index in primary advanced epithelial ovarian Cancer patients after complete Cytoreductive surgery: study of tumor Bank ovarian Cancer. Ann Surg Oncol. 2015;22(8):2729-37.

8. Llueca A, Serra A, Rivadulla I, Gomez L, Escrig J. Prediction of suboptimal cytoreductive surgery in patients with advanced ovarian cancer based on preoperative and intraoperative determination of the peritoneal carcinomatosis index. World J Surg Oncol. 2018;16(1):37.

9. Diaz-Gil D, Fintelmann FJ, Molaei S, Elmi A, Hedgire SS, Harisinghani MG. Prediction of 5-year survival in advanced-stage ovarian cancer patients based on computed tomography peritoneal carcinomatosis index. Abdom Radiol (NY). 2016;41(11):2196-202.
10. Prader S, Vollmar N, du Bois A, Heitz F, Schneider S, Ataseven B, et al. Pattern and impact of metastatic cardiophrenic lymph nodes in advanced epithelial ovarian cancer. Gynecol Oncol. 2019;152(1):76-81.

11. Cowan RA, Tseng J, Murthy V, Srivastava R, Long Roche KC, Zivanovic O, et al. Feasibility, safety and clinical outcomes of cardiophrenic lymph node resection in advanced ovarian cancer. Gynecol Oncol. 2017;147(2):262-6.

12. Boyd NF, Martin LJ, Yaffe MJ, Minkin S. Mammographic density and breast cancer risk: current understanding and future prospects. Breast Cancer Res. 2011;13(6):223.

13. Olsson A, Sartor H, Borgquist S, Zackrisson S, Manjer J. Breast density and mode of detection in relation to breast cancer specific survival: a cohort study. BMC Cancer. 2014;14:229.

14. Wernli KJ, O'Meara ES, Kerlikowske K, Miglioretti DL, Muller CY, Onega T, et al. Investigation of mammographic breast density as a risk factor for ovarian cancer. J Natl Cancer Inst. 2014;106(1):dit341-djt.

15. Manjer J, Carlsson S, Elmstahl S, Gullberg B, Janzon L, Lindstrom M, et al. The Malmo diet and Cancer study: representativity, cancer incidence and mortality in participants and non-participants. Eur J Cancer Prev. 2001;10(6): 489-99.

16. Manjer J, Elmstahl S, Janzon L, Berglund G. Invitation to a population-based cohort study: differences between subjects recruited using various strategies. Scand J Public Health. 2002;30(2):103-12.

17. Berglund G, Elmstahl S, Janzon L, Larsson SA. The Malmo diet and Cancer study. Design and feasibility. J Intern Med. 1993;233(1):45-51.

18. D'Orsi CJSE, Mendelson EB, Morris EA, et al. ACR BI-RADS ${ }^{\circledR}$ atlas, breast imaging reporting and data system. Reston: American College of Radiology; 2013.

19. Brändstedt J, Nodin B, Manjer J, Jirström K. Anthropometric factors and ovarian cancer risk in the Malmö diet and Cancer study. Cancer Epidemiol. 2011;35(5):432-7.

20. Coakley FV, Choi PH, Gougoutas CA, Pothuri B, Venkatraman E, Chi D, et al. Peritoneal metastases: detection with spiral $C T$ in patients with ovarian cancer. Radiology. 2002;223(2):495-9.

21. Laghi A, Bellini D, Rengo M, Accarpio F, Caruso D, Biacchi D, et al. Diagnostic performance of computed tomography and magnetic resonance imaging for detecting peritoneal metastases: systematic review and metaanalysis. Radiol Med. 2017;122(1):1-15.

22. du Bois A, Reuss A, Pujade-Lauraine E, Harter P, Ray-Coquard I, Pfisterer J. Role of surgical outcome as prognostic factor in advanced epithelial ovarian cancer: a combined exploratory analysis of 3 prospectively randomized phase 3 multicenter trials: by the Arbeitsgemeinschaft Gynaekologische Onkologie Studiengruppe Ovarialkarzinom (AGO-OVAR) and the Groupe d'Investigateurs Nationaux pour les etudes des cancers de I'Ovaire (GINECO). Cancer. 2009:115(6):1234-44.

23. Khoury-Collado F, Chi DS. Recent surgical management of ovarian cancer. J Obstet Gynaecol Res. 2011;37(5):379-82.

24. Brown G, Richards CJ, Bourne MW, Newcombe RG, Radcliffe AG, Dallimore NS, et al. Morphologic predictors of lymph node status in rectal cancer with use of high-spatial-resolution MR imaging with histopathologic comparison. Radiology. 2003;227(2):371-7.

25. Ramus SJ, Gayther SA. The contribution of BRCA1 and BRCA2 to ovarian cancer. Mol Oncol. 2009:3(2):138-50.

\section{Publisher's Note}

Springer Nature remains neutral with regard to jurisdictional claims in published maps and institutional affiliations.

Ready to submit your research? Choose BMC and benefit from:

- fast, convenient online submission

- thorough peer review by experienced researchers in your field

- rapid publication on acceptance

- support for research data, including large and complex data types

- gold Open Access which fosters wider collaboration and increased citations

- maximum visibility for your research: over $100 \mathrm{M}$ website views per year

At BMC, research is always in progress.

Learn more biomedcentral.com/submission 